\title{
Healthcare Costs Associated with Change in Body Mass Index in Patients with Type 2 Diabetes Mellitus in Spain The ECOBIM Study
}

\author{
Tatiana Dilla, ${ }^{1}$ Amparo Valladares, ${ }_{1}$ Claudia Nicolay, ${ }^{2}$ Javier Salvador, ${ }^{3}$ Jesús Reviriego ${ }^{1}$ \\ and María Costi ${ }^{1}$ \\ 1 Medical Department, Lilly, Alcobendas, Madrid, Spain \\ 2 Lilly Deutschland GmbH, Bad Homburg, Germany \\ 3 Department of Endocrinology and Nutrition, Clínica Universitaria de Navarra, Pamplona, Spain
}

Background: Weight management is considered a key therapeutic strategy in type 2 diabetes mellitus. However, little is known about the impact of weight loss or body mass index (BMI) reduction on type 2 diabetes-related healthcare costs. Objective: The aim of this study was to estimate the economic impact of change in BMI among patients with type 2 diabetes mellitus from the Spanish healthcare system perspective.

Methods: The ECOBIM study is an observational, non-interventional study in which data on BMI change and costs incurred by patients with type 2 diabetes were collected cross-sectionally and retrospectively for a 12-month period. Generalized linear mixed models were applied to estimate the effects of (i) BMI change in general (one-slope model); (ii) BMI gain and no BMI gain (two-slope model); and (iii) BMI gain and no BMI gain among obese and non-obese patients (four-slope model).

Results: We studied 738 patients with a mean (SD) age of 66 (11) years and BMI of $30.6(5.2) \mathrm{kg} / \mathrm{m}^{2}$. During the 12-month study period, $41.2 \%$ of patients gained BMI (BMI gainers) and 58.8\% experienced either loss $(52.2 \%)$ or no change $(6.6 \%)$ in BMI (non-BMI gainers). One-unit gain (or loss) in BMI was significantly $(\mathrm{p}<0.001)$ associated with a $2.4 \%$ cost increase (or decrease) [one-slope model]. Every unit gain in BMI was associated with a $20.0 \%$ increase in costs among BMI gainers while losing one unit was associated with an $8.0 \%$ decrease in costs among non-BMI gainers (two-slope model, $\mathrm{p}<0.01)$. The economic benefit associated with reducing one BMI unit was 9.4\% cost decrease in obese and $2.7 \%$ in non-obese patients (4-slope model).

Conclusion: An increase in BMI among patients with type 2 diabetes was associated with increased 1-year direct healthcare costs. A reduction in BMI was associated with appreciable short-term economic benefits, especially in obese patients. 


\section{Key points for decision makers}

- In Spanish patients with type 2 diabetes mellitus, increasing BMI was found to be associated with increasing healthcare costs during the study period, and decreasing BMI with decreasing costs, especially in obese patients

- Pharmacy costs were found to be significantly higher in type 2 diabetes patients who gained $\mathrm{BMI}$ than in those without a BMI increase

\section{Introduction}

Type 2 diabetes mellitus is one of the leading causes of morbidity and mortality in Europe. ${ }^{[1]}$ Currently, about 285 million people worldwide have diabetes and this number is expected to reach 439 million by $2030 .{ }^{[2]}$ The prevalence of diabetes mellitus in Spain is currently estimated at $8.7 \%$, and type 2 diabetes accounts for about $90 \%$ of cases. ${ }^{[3,4]}$ Type 2 diabetes and its complications confer a substantial economic burden on health systems and society that is expected to increase as the prevalence of diabetes increases. ${ }^{[1,5,6]}$ In Spain, during 2002, the total direct medical costs of type 2 diabetes have been estimated at between $€ 2.4$ and $€ 2.7$ billion, which corresponds to approximately $6.3-7.4 \%$ of total public health expenditure. ${ }^{[7]}$ Estimates of the mean type 2 diabetes annual direct costs in Spain are in the range of $€ 1290-€ 3009$ per patient. ${ }^{[7-10]}$

Patients with type 2 diabetes are at increased risk of cardiovascular disease owing to concomitant presence of cardiovascular risk factors such as obesity, hypertension, dyslipidaemia and tobacco use. ${ }^{[11]}$ Obesity is the most significant risk factor in the development of major complications associated with type 2 diabetes. ${ }^{[12,13]}$ According to a recent estimate, $84 \%$ of patients with type 2 diabetes in Spain were either pre-obese, defined by a body mass index (BMI) of $>25 \mathrm{~kg} / \mathrm{m}^{2}$ and $<30 \mathrm{~kg} / \mathrm{m}^{2}$, or obese $\left(\right.$ BMI $\left.\geq 30 \mathrm{~kg} / \mathrm{m}^{2}\right)$, ${ }^{[14]}$ although these estimations would be higher if body composition techniques were considered a diagnostic tool. ${ }^{[15]}$ The prevalence of type 2 diabetes increases with the severity of obesity. ${ }^{[16,17]}$ Together, type 2 diabetes and obesity lead to a higher incidence of diabetes-related complications and cardiovascular events, ${ }^{[18,19]}$ which translates into increased economic costs for national health systems. ${ }^{[1]}$ Likewise, a very recent study in diabetes patients with BMI $\geq 35 \mathrm{~kg} / \mathrm{m}^{2}$ reported that clinical benefits of bariatric surgery translated into considerable economic benefits. ${ }^{[20]}$ Furthermore, diabetes-related complications and/ or obesity adversely affect patients' healthrelated quality of life (HR-QOL), ${ }^{[21-24]}$ primarily in the physical domain. Although studies have assessed the clinical benefit of weight loss in patients with type 2 diabetes, ${ }^{[25-27]}$ little is known about the impact of weight loss or BMI reduction on type 2 diabetes care costs. The objective of the present study was to estimate the effect of BMI change in short-term economic costs of type 2 diabetes care from the Spanish healthcare system perspective.

\section{Materials and Methods}

\section{Study Design}

The ECOBIM (Economic Impact of BMI on Cost Associated with the Management of Patients with type 2 Diabetes Mellitus) study was an observational, non-interventional, multicentre study conducted in Spain. It consisted of a 12-month observation period (study reference period) for which data were collected retrospectively and cross-sectionally from patients' medical charts at the study visit (figure 1). All data were provided during usual care and no additional visits, tests or interventions were required. The protocol was approved by Hospital Universitario La Paz ethics committee (Madrid, Spain) and conducted in accordance with the Spanish regulation for observational studies and the Declaration of Helsinki. Patients volunteered for the study and 


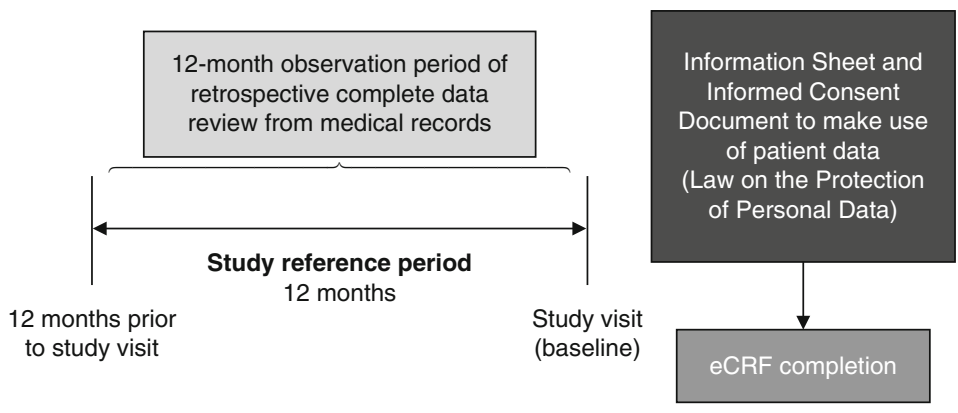

Fig. 1. Study design. eCRF=electronic case report form.

authorized the use of their data according to defined provisions in Law 15/1999 of 13 December on the Protection of Personal Data.

\section{Study Population and Investigators}

Patients included men and women aged over 30 years who had been diagnosed with type 2 diabetes by the investigator based on the American Diabetes Association (ADA) criteria ${ }^{[4]}$ at least 24 months prior to their inclusion. Eligible patients had been followed during the normal course of outpatient care, either in the hospital or in the investigator's private practice, and had relevant information available in their medical records for at least 24 months prior to study inclusion (information regarding weight was collected [and used] from medical records 12, 18 and 24 months prior to the beginning of the study). Patients were excluded if they had been diagnosed with type 1 diabetes mellitus or diabetes secondary to other diseases, were female patients pregnant during the observation period, or had participated in any other clinical study 24 months prior to the inclusion in the ECOBIM study. Each site could recruit up to six patients on consecutive days. For each day, the first patient meeting the screening criteria and with a scheduled visit during the study inclusion period was included. Participating centres were selected so that the geographic distribution and investigator type (general practitioners and specialists) were representative of the physician population treating patients with type 2 diabetes in Spain.

\section{Data Collection and Cost Assessment}

At the study visit, sociodemographic, clinical and healthcare resource utilization data related to diabetes and its complications were collected from the medical records for the 12-month study reference period. Clinical data collected included anthropometric characteristics, time since type 2 diabetes diagnosis, diabetes-related complications, cardiovascular risk factors, glycaemic control (glycosylated haemoglobin $\mathrm{A}_{1 \mathrm{c}}\left[\mathrm{HbA}_{1 \mathrm{c}}\right]$, and fasting plasma glucose [FPG]). Healthcare resource data included visits to healthcare professionals (primary care and specialist physicians, and other professionals such as dieticians or podiatrists), emergency room visits, hospitalizations, diabetes treatment, other related co-morbidities, and use of blood glucose monitoring strips.

The key variables were the change in BMI and direct healthcare costs over the 12-month study reference period. BMI was calculated from weight and height measurements at the study visit and from weight measurements at $12 \pm 1$ months prior to the study visit (the beginning of the study reference period). Healthcare costs were collected over the same 12-month period. In order to avoid under-reporting of healthcare resource usage (based on medical record data), patients were asked several questions during the study visit regarding their use of healthcare resources during the previous (observational period) year. These questions served as a quality check of the medical record entries and elicited any missing data. Costs related to direct healthcare resources were obtained from the OBLIKUE database of Spanish 
healthcare costs for the year 2008. ${ }^{[28]}$ Unit cost of medications for the treatment of type 2 diabetes and related co-morbidities were obtained from the BOT database (General Council of Official Colleges of Pharmacists of Spain). ${ }^{[29]}$ In addition, patients completed two HR-QOL questionnaires at the study visit: the EuroQol-5D (EQ-5D) health questionnaire $^{[30]}$ and a Spanish version of the Diabetes Quality of Life (DQOL) questionnaire. ${ }^{[31]}$

\section{Statistical Analysis}

The study was planned to include 779 patients, allowing the detection of a low correlation between BMI and direct diabetes costs $(0.1)$ at a significance level of 0.05 and with a statistical power of 0.80 . Based on the change in BMI during the study reference period, the patients were classified as BMI gainers (change in BMI $>0$ ) and non-BMI gainers (patients who experienced either a loss or no change in BMI). The demographic and clinical characteristics for these two subgroups were assessed using descriptive summary statistics. Means and standard deviations (SDs) were calculated for continuous variables. Absolute frequencies and percentages were calculated for categorical variables. All percentage calculations were based on the number of patients studied. Univariate comparisons were performed between BMI gainers and non-BMI gainers: Chi-square tests or the Cochran-Armitage trend test were used to compare categorical variables. Wilcoxon tests and analyses of covariance were used to compare continuous variables. Mean, SD and median for direct 1-year healthcare costs in the BMI-gainer and non-BMI-gainer subgroups were also calculated and compared descriptively using Wilcoxon tests. In addition, 95\% confidence intervals for mean cost were derived via bootstrapping.

Generalized linear mixed models (GLMMs) provide a flexible way to model production traits that do not satisfy the assumptions of an ordinary least-square regression, e.g. cost data. ${ }^{[32]}$ Therefore, the economic impact of BMI change on type 2 diabetes total direct costs was assessed using three GLMMs with a log link function and gamma error distribution. The estimated regres- sion coefficient was transformed to euros and expressed as percentage change in the total direct cost for each unit $\left(1 \mathrm{~kg} / \mathrm{m}^{2}\right)$ increase or decrease in BMI.

In GLMM model 1 (one-slope model), the direct cost of diabetes (absolute values) was analysed according to the BMI at 12 months prior to the study visit, including the cost as dependent variable and the BMI as independent variable. This allowed the estimation of the impact that an increase of one BMI unit had on the direct cost per patient. In GLMM model 2 (twoslope model), the direct cost of diabetes was analysed according to the change in BMI from baseline to 12 months during the study reference period (i.e. gain vs no gain), and the interaction between both variables. Statistically significant differences in cost between BMI gainers and nonBMI gainers could be detected owing to the addition of the interaction term in the model. This analysis resulted in separate slope estimates for BMI gainers and non-BMI gainers.

Based on GLMM model 2, GLMM model 3 (four-slope model) allowed the study of statistically significant differences in direct diabetes costs among BMI gainers and non-BMI gainers according to obesity status, i.e. in patients defined according to the World Health Organization $^{[13]}$ as obese (BMI $\geq 30 \mathrm{~kg} / \mathrm{m}^{2}$ ) or non-obese $\left(\mathrm{BMI}<30 \mathrm{~kg} / \mathrm{m}^{2}\right)$ at the study visit. Change in BMI during the study reference period, obesity status at the study visit and the corresponding interaction terms were included as independent regression variables. This analysis resulted in separate slope estimates at baseline for (i) BMI gainer, obese patients; (ii) BMI gainer, non-obese patients; (iii) non-BMI gainer, obese patients; and (iv) non-BMI gainer, non-obese patients.

Variables that could potentially confound the observed associations were included in all these models as independent regression variables. These included baseline sociodemographic and clinical variables, diabetes treatment information, DQOL, EQ-5D, work productivity, and diabetes-related microvascular and macrovascular complications. For all three GLMM models, the selection process was as follows. First, individual GLMMs were performed (with direct 
cost as dependent variable and each variable as independent regression variable) in order to detect factors related to the total direct cost. In a second step, the variables that were found to be significant in the individual models were then used to build the multivariate model. Results regarding the first step of the multivariate model build are provided in table S1 of the Supplemental Digital Content, http://links.adisonline. com/APZ/A62. Missing values were not imputed. These three multivariate GLMMs were also replicated using weight instead of BMI.

Statistical significance was evaluated at the 0.05 level. Statistical Analysis System ${ }^{\circledR}$ software version 8 (SAS Institute, Inc., Cary, NC, USA) was used for all analyses.

\section{Results}

The study was conducted in Spain by 80 investigators (25 primary care physicians, 27 endocrinologists and 28 specialists in internal medicine) at 80 sites located either in hospitals or private practices (these data refer only to sites and investigators who contributed the 757 patients entered in the study). A total of 757 patients entered the study between March and November 2008,738 of whom were eligible for analysis. Of the eligible patients, 304 (41.2\%) were categorized as BMI gainers and $434(58.8 \%)$ as non-BMI gainers. Among the non-BMI gainers, 385 (52.2\% of the total eligible population) showed BMI loss and $49(6.6 \%)$ showed no BMI change.

\section{Patient Characteristics}

Overall, the mean age was 66 years and $54.2 \%$ of the 738 patients were males (table I). Most patients were Caucasian $(97.0 \%), 71.8 \%$ were educated to primary level at most, $42.7 \%$ were retired, and $59.8 \%$ had never smoked. The number of patients unable to work because of diabetes was relatively low (1.9\%), so was the number of patients unable to work due to other reasons (BMI gainers: $4.9 \%$ and non-BMI gainers: $2.1 \%$ ). The mean time since diabetes diagnosis was statistically significantly higher in BMI gainers (12 years) than non-BMI gainers (10 years) $[\mathrm{p}<0.01]$. Most patients had been on non-insulin treatment only during the last 12 months (BMI gainers 53.3\%; non-BMI gainers $67.7 \%$ ). A quarter (25.5\%) had used both insulin and non-insulin treatment (BMI gainers $32.9 \%$ and non-BMI gainers $20.3 \%$ ) and $8.9 \%$ (BMI gainers $10.9 \%$, non-BMI gainers $7.6 \%$ ) had used only insulin. Overall, 46 patients $(6.2 \%)$ initiated insulin during the 12-month observational period. Regarding the use of metformin, $160(52.6 \%)$ of the BMI gainers and $294(67.4 \%)$ of non-BMI gainers had used metformin alone or in combination with insulin or other oral antidiabetic drugs (sulphonylureas and thiazolidinediones).

BMI gainers and non-BMI gainers had a similar mean waist circumference 12 months prior to baseline, but BMI gainers had a statistically significantly greater waist circumference than nonBMI gainers at the study visit $(\mathrm{p}<0.001)$ [table II]. BMI gainers also had significantly higher mean $\mathrm{HbA}_{1 \mathrm{c}}$ and FPG values than non-BMI gainers at the study visit (both $\mathrm{p}<0.001$ ). With the exception of triglycerides $(p=0.008)$, no statistically significant differences were observed for lipids and blood pressure at the study visit (table II).

\section{Direct Healthcare Costs}

During the study reference period, the average 1-year total direct healthcare cost for the entire study population was $€ 2336.67$ per patient (median $€ 1683.27$ ). This cost comprised a pharmacy cost of $€ 1512.48$ (median $€ 1192.40$ ) and a medical cost of $€ 828.29$ (median $€ 242.56$ ) [table III]. The mean pharmacy cost was higher than the medical cost in both the BMI gainers and the nonBMI gainers. The bulk of the pharmacy costs in both groups (approximately 75\%) was due to costs of blood glucose monitoring and diabetesrelated medication. If we compare between groups, the mean pharmacy cost was significantly higher $(\mathrm{p}=0.0054)$ in the BMI gainers than in the non-BMI gainers. This finding was attributable to significantly higher costs for insulin $(\mathrm{p}<0.001)$ and for blood glucose monitoring $(\mathrm{p}<0.001)$ among BMI gainers. The mean medical cost was lower in the BMI gainers (€784 vs $€ 859$ ), but the difference was not statistically significant. 
Table I. Sociodemographic characteristics (at the study visit) of the study population by BMI cohort ${ }^{a, b}$

\begin{tabular}{|c|c|c|c|}
\hline Characteristic & $\begin{array}{l}\text { BMI gainers } \\
(n=304)\end{array}$ & $\begin{array}{l}\text { Non-BMI gainers } \\
(n=434)\end{array}$ & $\begin{array}{l}\text { Total } \\
(\mathrm{N}=738)\end{array}$ \\
\hline Mean age, years (SD) & $65(11)$ & $66(11)$ & $66(11)$ \\
\hline \multicolumn{4}{|l|}{ Gender, n (\%) } \\
\hline Male & $161(53.0)$ & $239(55.1)$ & $400(54.2)$ \\
\hline Female & $143(47.0)$ & $195(44.9)$ & $338(45.8)$ \\
\hline \multicolumn{4}{|l|}{ Race, n (\%) } \\
\hline Caucasian & $295(97.0)$ & $421(97.0)$ & $716(97.0)$ \\
\hline Hispanic & $8(2.6)$ & $11(2.5)$ & $19(2.6)$ \\
\hline Others & $1(0.3)$ & $2(0.5)$ & $3(0.4)$ \\
\hline Mean time since diagnosis, years $(\mathrm{SD})^{\mathrm{c}}$ & $12(8)$ & $10(7)$ & $11(8)$ \\
\hline \multicolumn{4}{|l|}{ Has the patient ever smoked? n (\%) } \\
\hline No & $169(55.6)$ & $272(62.7)$ & $441(59.8)$ \\
\hline Yes & $135(44.4)$ & $162(37.3)$ & $297(40.2)$ \\
\hline \multicolumn{4}{|l|}{ Is the patient currently smoking? $\mathrm{n}(\%)^{\mathrm{d}}$} \\
\hline No & $94(69.6)$ & $119(73.5)$ & $213(71.7)$ \\
\hline Yes & $41(30.4)$ & $43(26.5)$ & $84(28.3)$ \\
\hline Number of cigarettes per day (last 12 months), $n(S D)^{d}$ & $3.9(7.5)$ & $4.4(8.5)$ & $4.2(8.0)$ \\
\hline \multicolumn{4}{|l|}{ Environment, n (\%) } \\
\hline Urban & $220(72.4)$ & $290(66.8)$ & $510(69.1)$ \\
\hline Rural & $43(14.1)$ & $82(18.9)$ & $125(16.9)$ \\
\hline Semi-rural & $41(13.5)$ & $62(14.3)$ & $103(14.0)$ \\
\hline \multicolumn{4}{|l|}{ Education, $\mathrm{n}(\%)^{\mathrm{e}}$} \\
\hline Illiterate/no formal education & $57(18.8)$ & $81(18.7)$ & $138(18.7)$ \\
\hline Primary & $176(57.9)$ & $216(49.8)$ & $392(53.1)$ \\
\hline Secondary & $54(17.8)$ & $96(22.1)$ & $150(20.3)$ \\
\hline University & $16(5.3)$ & $40(9.2)$ & $56(7.6)$ \\
\hline Missing & $1(0.3)$ & $1(0.2)$ & $2(0.3)$ \\
\hline \multicolumn{4}{|l|}{ Occupation (last 3 months), n (\%) } \\
\hline Retired & $124(40.8)$ & $191(44.0)$ & $315(42.7)$ \\
\hline Fulltime employed & $73(24.0)$ & $115(26.5)$ & $188(25.5)$ \\
\hline House-keeping & $77(25.3)$ & $91(21.0)$ & $168(22.8)$ \\
\hline Unable to work for reasons not related to diabetes & $15(4.9)$ & $9(2.1)$ & $24(3.3)$ \\
\hline Unemployed & $6(2.0)$ & $12(2.8)$ & $18(2.4)$ \\
\hline Unable to work because of diabetes & $6(2.0)$ & $8(1.8)$ & $14(1.9)$ \\
\hline Student & $2(0.7)$ & $4(0.9)$ & $6(0.8)$ \\
\hline Other & $1(0.3)$ & $4(0.9)$ & $5(0.7)$ \\
\hline \multicolumn{4}{|l|}{ Diabetes treatment (last 12 months), $\mathrm{n}(\%)^{\mathrm{g}}$} \\
\hline Non-insulin only & $162(53.3)$ & $294(67.7)$ & $456(61.8)$ \\
\hline Both insulin and non-insulin & $100(32.9)$ & $88(20.3)$ & $188(25.5)$ \\
\hline Insulin only & $33(10.9)$ & $33(7.6)$ & $66(8.9)$ \\
\hline None & $9(3.0)$ & $19(4.4)$ & $28(3.8)$ \\
\hline \multicolumn{4}{|l|}{ Non-insulin treatment (12 months prior to study visit), $\mathrm{n}(\%)$} \\
\hline Metformin only & $123(40.5)$ & $181(41.7)$ & $304(41.2)$ \\
\hline Sulphonylurea only & $34(11.2)$ & $33(7.6)$ & $67(9.1)$ \\
\hline
\end{tabular}


Table I. Contd

\begin{tabular}{|c|c|c|c|}
\hline Characteristic & $\begin{array}{l}\text { BMI gainers } \\
(\mathrm{n}=304)\end{array}$ & $\begin{array}{l}\text { Non-BMI gainers } \\
(n=434)\end{array}$ & $\begin{array}{l}\text { Total } \\
(\mathrm{N}=738)\end{array}$ \\
\hline TZDs only & $6(2.0)$ & $17(3.9)$ & $23(3.1)$ \\
\hline Combination of 2 oral antidiabetics & $32(10.5)$ & $55(12.7)$ & $87(11.8)$ \\
\hline Combination of 3 oral antidiabetics & $8(2.6)$ & $14(3.2)$ & $22(3.0)$ \\
\hline Other & $36(11.8)$ & $49(11.3)$ & $85(11.5)$ \\
\hline \multicolumn{4}{|c|}{ Type of BG monitoring during 12 months prior to study visit, $\mathrm{n}(\%)$} \\
\hline None & $79(26.0)$ & $163(37.6)$ & $242(32.8)$ \\
\hline Urine test strips only & $0(0.0)$ & $3(0.7)$ & $3(0.4)$ \\
\hline Blood glucose monitoring strips only & $218(71.7)$ & $260(59.9)$ & $478(64.8)$ \\
\hline Both urine and blood glucose strips & $7(2.3)$ & $8(1.8)$ & $15(2.0)$ \\
\hline \multicolumn{4}{|c|}{$\begin{array}{l}\text { a BMI gainers: patients whose BMI increased during the } 12 \text { months prior to the study visit. Non-BMI gainers: patients who experienced no } \\
\text { gain in BMI, i.e. either a loss }(n=385) \text { or no change }(n=49) \text { during the } 12 \text { months prior to the study visit. }\end{array}$} \\
\hline \multicolumn{4}{|c|}{$\begin{array}{l}\text { b Continuous data are means. Wilcoxon tests were used for statistical comparisons of continuous variables. Chi-square tests and the } \\
\text { Cochran-Armitage trend test (for Education only, excluding missing values) were used for statistical comparisons of categorical variables. }\end{array}$} \\
\hline \multicolumn{4}{|c|}{ c $\quad \mathrm{p}<0.01$ comparing $\mathrm{BMI}$ gainers and non-BMI gainers. } \\
\hline \multicolumn{4}{|c|}{ d Only patients who have ever smoked $=100 \%$. } \\
\hline \multicolumn{4}{|c|}{ e $\quad p<0.05$ comparing BMI gainers and non-BMI gainers taking into account all categories under 'Education'. } \\
\hline \multicolumn{4}{|l|}{ f No statistical comparison performed. } \\
\hline \multicolumn{4}{|c|}{ g $\quad p<0.001$ comparing BMl gainers and non-BMl gainers, taking into account all categories under 'Diabetes treatment during the last 12 months'. } \\
\hline \multicolumn{4}{|c|}{$\mathbf{B G}=$ blood glucose $\mathbf{B M I}=$ body mass index; $\mathbf{n}=$ number of patients; $\mathbf{N}=$ total population size; $\mathbf{T Z D}=$ thiazolidinediones } \\
\hline
\end{tabular}

\section{Healthcare Costs and BMI Change}

Three GLMMs were used to explore the association of diabetes-related healthcare costs with BMI change during the 12-month study reference period. Due to missing values, only data of 517 patients could be used (BMI gainers: 198 patients; non-BMI gainers: 319 patients). These patients had a mean age of 65 years and $57.6 \%$ were male. The mean time since diagnosis of diabetes was 11 years for BMI gainers and 9 years for non-BMI gainers $(p=0.079)$. The majority of patients had never smoked $(59.0 \%)$. Most patients had been on non-insulin treatment only during the last 12 months (BMI gainers 57.6\%; non-BMI gainers $72.4 \%$ ). Overall, $22.8 \%$ had used both insulin and non-insulin treatment (BMI gainers $31.3 \%$ and non-BMI gainers $17.6 \%$ ) and $6.2 \%$ (BMI gainers $7.6 \%$; non-BMI gainers $5.3 \%$ ) had used only insulin. Regarding the use of metformin, $112(56.6 \%)$ of the BMI gainers and 177 (55.5\%) of non-BMI gainers had used metformin alone or in combination.

In model 1 (one-slope model), a unit gain in BMI was statistically significantly $(\mathrm{p}<0.001)$ associated with an increase of $2.4 \%$ in total direct costs (figure 2 and table IV). When the effects of BMI gain and no BMI gain during the study reference period were assessed separately for BMI gainers and non-BMI gainers (model 2, twoslope model), a one-unit change in BMI was associated in BMI gainers with a $20.0 \%$ increase in costs, but in non-BMI gainers with an $8.0 \%$ decrease in costs $(p<0.01$ for the comparison of subgroups, table IV).

Model 3 (four-slope model) examined the association of BMI change with 1-year direct costs during the study reference period according to patients' obesity status at the study visit. Among non-BMI gainers, a one-unit decrease in BMI was associated with a decrease of $9.4 \%$ in total direct costs in obese patients and a decrease of $2.7 \%$ in non-obese patients (table IV). Among BMI gainers, a one-unit increase in BMI was associated with an increase of $19.6 \%$ and $18.7 \%$ in total direct costs in obese and non-obese patients, respectively.

Similar patterns of results were obtained when weight, instead of BMI, was applied in the three GLMM models. In model 1 , a gain of $1 \mathrm{~kg}$ was significantly $(p=0.003)$ associated with an increase 
Table II. Clinical characteristics of the study population by BMI cohort ${ }^{\mathrm{a}}$

\begin{tabular}{|c|c|c|c|c|c|c|c|c|}
\hline \multirow[t]{2}{*}{ Characteristic } & \multicolumn{2}{|c|}{$\begin{array}{l}\text { BMI gainers }[n=304] \\
\text { Mean }(S D)\end{array}$} & \multicolumn{2}{|c|}{$\begin{array}{l}\text { Non-BMI gainers }[\mathrm{n}=434] \\
\text { Mean }(\mathrm{SD})\end{array}$} & \multicolumn{2}{|l|}{$p$-Value ${ }^{b}$} & \multicolumn{2}{|l|}{$\begin{array}{l}\text { Total }[\mathrm{N}=738] \\
\text { Mean (SD) }\end{array}$} \\
\hline & $\begin{array}{l}\text { Prior } \\
12 \text { months }\end{array}$ & Study visit & $\begin{array}{l}\text { Prior } \\
12 \text { months }\end{array}$ & Study visit & $\begin{array}{l}\text { Prior } \\
12 \text { months }\end{array}$ & $\begin{array}{l}\text { Study } \\
\text { visit }\end{array}$ & $\begin{array}{l}\text { Prior } \\
12 \text { months }\end{array}$ & Study visit \\
\hline $\mathrm{HbA}_{1 \mathrm{c}}, \%$ & $7.4(1.8)$ & $7.3(1.6)$ & $7.2(1.6)$ & $6.8(1.7)$ & NA & $<0.001$ & $7.3(1.7)$ & $7.0(1.7)$ \\
\hline FPG, mg/dL & $149.8(50.9)$ & $147.5(50.2)$ & $143.3(43.6)$ & $133.1(41.9)$ & NA & $<0.001$ & $146.0(46.8)$ & $139.0(46.0)$ \\
\hline Weight, kg & $81.2(15.6)$ & $83.5(16.0)$ & $81.7(13.4)$ & $79.2(13.0)$ & 0.413 & $N A^{c}$ & $81.5(14.3)$ & $81.0(14.5)$ \\
\hline $\mathrm{BMI}, \mathrm{kg} / \mathrm{m}^{2}$ & $30.9(5.7)$ & $31.8(5.8)$ & $30.7(4.8)$ & $29.7(4.6)$ & 0.789 & $N A^{c}$ & $30.8(5.2)$ & $30.6(5.2)$ \\
\hline Waist circumference, $\mathrm{cm}$ & $102.6(13.6)$ & $104.3(13.8)$ & $102.4(12.2)$ & $100.8(11.8)$ & NA & $<0.001$ & $102.5(12.8)$ & $102.3(12.7)$ \\
\hline HDL-cholesterol, mg/dL & $49.2(13.2)$ & $48.2(12.7)$ & $48.9(13.0)$ & $48.3(13.4)$ & NA & 0.954 & $49.0(13.1)$ & $48.3(13.1)$ \\
\hline LDL-cholesterol, mg/dL & $109.7(30.5)$ & $105.1(31.1)$ & $117.5(35.0)$ & $107.0(32.6)$ & NA & 0.232 & $114.3(33.4)$ & $106.2(32.0)$ \\
\hline Total cholesterol, mg/dL & $188.6(43.1)$ & $180.0(37.9)$ & $194.0(40.7)$ & $179.1(37.6)$ & NA & 0.102 & $191.8(41.8)$ & $179.5(37.7)$ \\
\hline Triglycerides, mg/dL & $141.8(92.0)$ & $142.4(83.3)$ & $149.8(94.5)$ & $135.0(71.6)$ & NA & 0.008 & $146.6(93.5)$ & $138.0(76.7)$ \\
\hline Systolic BP, mmHg & $136.9(15.5)$ & $137.3(18.4)$ & $137.0(16.3)$ & $136.0(14.4)$ & NA & 0.180 & $137.0(16.0)$ & $136.5(16.2)$ \\
\hline Diastolic BP, mmHg & $77.9(10.1)$ & $77.5(11.1)$ & $78.4(9.9)$ & $77.4(9.7)$ & NA & 0.562 & $78.2(10.0)$ & $77.4(10.3)$ \\
\hline \multicolumn{9}{|c|}{$\begin{array}{l}\text { a BMI gainers: patients whose BMI increased during the } 12 \text { months prior to the study visit. Non-BMl gainers: patients who experienced no } \\
\text { gain in BMI, i.e. either a loss }(n=385) \text { or no change }(n=49) \text { during the } 12 \text { months prior to the study visit. }\end{array}$} \\
\hline \multicolumn{9}{|c|}{$\begin{array}{l}\text { b For all variables except weight and BMI, comparisons were performed by analyses of covariance with the value at study visit as the } \\
\text { dependant variable, the BMI cohort as independent factor and the value at } 12 \text { months prior to the study visit as covariable. }\end{array}$} \\
\hline \multicolumn{9}{|c|}{$\begin{array}{l}\text { c Wilcoxon tests were used for the statistical comparisons of weight and BMI. No analyses of covariance were performed as these variables } \\
\text { were included in the definition of BMI cohorts. }\end{array}$} \\
\hline
\end{tabular}

of $0.8 \%$ in total direct costs. When weight changes during the study reference period were modelled separately for weight gainers (patients who experienced gain in weight) and non-weight gainers (patients who experienced either loss or no change in weight), every unit gain in weight was associated with a $7.6 \%$ increase in total direct costs, while a loss of $1 \mathrm{~kg}$ was associated with a $2.8 \%$ decrease in total direct costs (model 2). According to model 3, for the non-weight gainers, the economic benefit association with a reduction in weight was greater in obese patients $(3.4 \%$ decrease in total direct costs per $1 \mathrm{~kg}$ of weight lost) than in non-obese patients $(0.7 \%$ decrease per $1 \mathrm{~kg}$ of weight lost). Among weight gainers, a $1 \mathrm{~kg}$ increase in weight was associated with an increase of $7.8 \%$ and $6.4 \%$ in total direct costs in obese and non-obese patients, respectively.

\section{Discussion}

Obesity is a significant determinant of healthcare costs, since it predisposes patients to chronic and costly medical conditions such as type 2 diabetes. ${ }^{[33]}$ The observational ECOBIM study was designed to assess the relationship between 1 -year direct healthcare costs and BMI change in patients with type 2 diabetes in Spain. Its results have important implications for clinicians involved in the management of patients with type 2 diabetes and the associated complications and co-morbidities.

Mean pharmacy costs over 1 year were almost twice the medical costs in both the BMI-gainers and the non-BMI-gainers groups within the ECOBIM population, owing mainly to costs of blood glucose testing and diabetes-related medication. This is in line with a previous study on the economic costs associated with type 2 diabetes in Spain. ${ }^{[8]}$ The authors reported that medications were the major cost driver ( $42 \%$ of annual direct healthcare costs per patient), with non-diabetesrelated drugs accounting for the main proportion in the overall pharmacological costs $(76 \%)$. Focusing on the difference between both groups in the pharmacy costs, the higher percentage of 
patients with insulin treatment among BMI gainers (44\% vs $28 \%$ ) could explain the approximately 1.5 -fold higher costs for insulin treatment and blood glucose monitoring in this cohort. In contrast to the pharmacy costs, the mean medical cost in ECOBIM was approximately $9 \%$ lower in BMI gainers than in non-BMI gainers. This difference was not statistically significant and its importance is unclear. Mean hospitalization costs were statistically significantly higher in nonBMI gainers. As the variability of hospitalization costs was also large in this group compared with the BMI gainers, mean costs for non-BMI gainers may have been influenced by some patients with very long stays at the hospital and therefore very high individual costs. Although there is some evidence for a reduction of healthcare costs in patients at very high BMI levels $\left(>36 \mathrm{~kg} / \mathrm{m}^{2}\right)$, increasing body mass is directly associated with an increasing use of healthcare services over the range of BMI observed in the ECOBIM study. ${ }^{[34]}$

Overall, among ECOBIM participants, a oneunit gain in BMI was statistically significantly associated with a $2.4 \%$ increase in total direct costs $(\mathrm{p}<0.001)$, a one-unit change in BMI gainers was associated with a $20.0 \%$ increase in total costs, while in non-BMI gainers, a one-unit decrease in BMI was associated with an $8.0 \%$ decrease in total costs $(\mathrm{p}<0.01$ for the comparison between BMI/non-BMI gainers). The estimated

Table III. BMI changes and direct healthcare costs among BMI gainers and non-BMI gainers ${ }^{a, b}$

\begin{tabular}{|c|c|c|c|}
\hline Variable & $\begin{array}{l}\text { BMl gainers } \\
(n=304)\end{array}$ & $\begin{array}{l}\text { Non-BMl gainers } \\
(n=434)\end{array}$ & $\mathrm{p}$-Value \\
\hline Baseline BMI, kg/m² & $31.81(5.84)$ & $29.73(4.58)$ & $<0.001$ \\
\hline Absolute BMI change, $\mathrm{kg} / \mathrm{m}^{2}$ & $0.87(0.72)$ & $-0.96(1.12)$ & \\
\hline \multicolumn{4}{|c|}{ 1-year direct healthcare costs during study reference period, $€$} \\
\hline Total & $\begin{array}{l}2452.62(2214.87) \\
{[2235.43,2734.26]}\end{array}$ & $\begin{array}{l}2255.45^{\mathrm{c}}(2387.36) \\
{[2047.16,2512.44]}\end{array}$ & 0.053 \\
\hline Pharmacy costs & $\begin{array}{l}1668.67(1301.88) \\
{[1531.60,1815.00]}\end{array}$ & $\begin{array}{l}1402.57^{\mathrm{C}}(1257.51) \\
{[1285.28,1541.59]}\end{array}$ & 0.005 \\
\hline Insulin treatment & $\begin{array}{l}229.63(342.60) \\
{[195.87,271.46]}\end{array}$ & $\begin{array}{l}143.73(293.33) \\
{[116.87,172.88]}\end{array}$ & $<0.001$ \\
\hline Non-insulin treatment & $\begin{array}{l}196.25(296.36) \\
{[168.58,230.61]}\end{array}$ & $\begin{array}{l}192.96(274.23) \\
{[168.51,219.51]}\end{array}$ & 0.571 \\
\hline Diabetes-related medication ${ }^{d}$ & $\begin{array}{l}552.99(620.47) \\
{[486.90,627.46]}\end{array}$ & $\begin{array}{l}562.72(858.68) \\
{[491.72,667.45]}\end{array}$ & 0.317 \\
\hline Blood glucose monitoring & $\begin{array}{l}689.80(842.19) \\
{[598.62,795.06]}\end{array}$ & $\begin{array}{l}496.70(672.71) \\
{[440.13,567.31]}\end{array}$ & 0.001 \\
\hline Medical costs & $\begin{array}{l}783.95(1717.41) \\
{[636.11,1040.88]}\end{array}$ & $\begin{array}{l}859.35^{\mathrm{c}}(1776.29) \\
{[723.29,1061.47]}\end{array}$ & 0.414 \\
\hline Healthcare professional visits & $\begin{array}{l}259.99(438.64) \\
{[218.75,319.92]}\end{array}$ & $\begin{array}{l}230.10(287.38) \\
{[205.28,258.09]}\end{array}$ & 0.828 \\
\hline Additional healthcare visits & $\begin{array}{l}87.58(154.41) \\
{[74.53,108.03]}\end{array}$ & $\begin{array}{l}87.09(127.68) \\
{[76.17,100.16]}\end{array}$ & 0.811 \\
\hline Hospitalization costs & $\begin{array}{l}436.38(1520.18) \\
{[303.93,653.86]}\end{array}$ & $\begin{array}{l}542.16(1612.62) \\
{[419.91,738.92]}\end{array}$ & 0.036 \\
\hline \multicolumn{4}{|c|}{$\begin{array}{l}\text { Non-BMI gainers: patients who experienced no gain in BMI, i.e. either a loss }(n=385) \text { or no change }(n=49) \text { during the } 12 \text { months prior to the } \\
\text { study visit. }\end{array}$} \\
\hline \multicolumn{4}{|l|}{$\begin{array}{l}\text { b All values are mean (SD). In a } \\
\text { Wilcoxon tests were used for }\end{array}$} \\
\hline \multicolumn{4}{|c|}{$\begin{array}{l}\text { For non-BMI gainers, missing values account for the difference between the total healthcare cost and the sum of medical and pharmacy } \\
\text { costs. }\end{array}$} \\
\hline \multicolumn{4}{|c|}{ d Diabetes-related medication: other than insulin and OADs. } \\
\hline \multicolumn{4}{|c|}{$\mathbf{B M I}=$ body mass index; $\mathbf{O A D}=$ oral antidiabetic medication.} \\
\hline
\end{tabular}




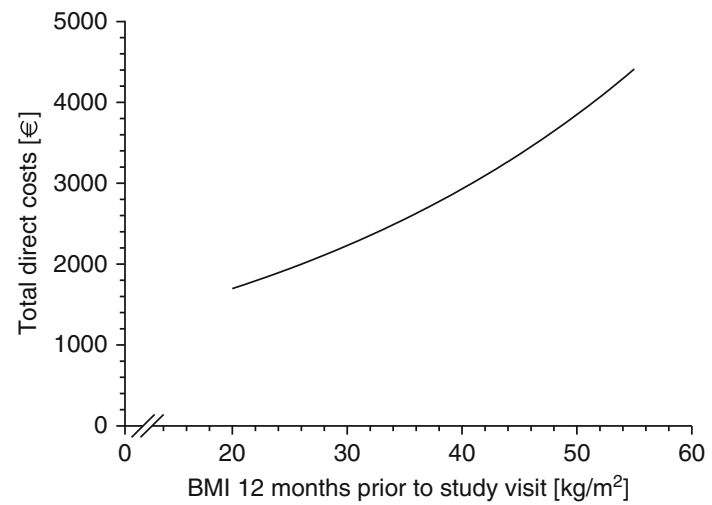

Fig. 2. Total direct costs relative to body mass index (BMI) at 12 months prior to the study visit. This figure is a visualization of a simplified model 1, with BMI at 12 months prior to study visit as the only independent factor.

economic benefit of BMI reduction was approximately 3 -fold greater in obese patients than in non-obese patients. These results are consistent with previous findings. Over a decade ago, it was estimated that an increase of one BMI unit among the general population in the US was associated with a $7 \%$ increase in total healthcare expenditure in males and a $16 \%$ increase in females. This increase in costs was attributed to the increased risk of chronic illnesses such as type 2 diabetes, although no significant relationship was observed when patients with specific illnesses were analysed. ${ }^{[34]}$ Another study that combined information from patient surveys, medical chart reviews and health insurance claims estimated that, among individuals with type 2 diabetes, every unit increase in BMI (over $30 \mathrm{~kg} / \mathrm{m}^{2}$ ) increased annual direct medical costs by $1 \% .^{[35]}$ More recently, $\mathrm{Yu}$ et al. ${ }^{[33]}$ analysed healthcare database information in the US and found that the mean total healthcare cost over 12 months was approximately $30 \%$ higher among patients with type 2 diabetes who gained weight over a 6-month observation period than among those who did not gain weight $(\mathrm{p}=0.046)$. Diabetesrelated costs were $14 \%$ higher among weight gainers than non-weight gainers $(p=0.006)$. According to a GLMM analysis, a $1 \%$ change in weight was associated with an approximately $3 \%$ change in total diabetes-related costs $(\mathrm{p}<0.01)$. When modelled separately, weight loss was sig- nificantly associated with a reduction in costs, while weight gain was not statistically significantly associated with an increase. As in the present study, the benefit of weight loss was most pronounced in obese patients, in whom a $1 \%$ reduction in weight was associated with a $6.7 \%$ decrease in diabetes-related costs $(p<0.01) .{ }^{[34]}$

Further evidence supports the conclusion that weight loss is associated with a reduction of economic costs among obese patients with type 2 diabetes. A small, prospective study assessed the effect of an intensive, 12-week weight reduction programme on prescription costs in obese patients with type 2 diabetes $(n=40) .{ }^{[36]}$ The mean observed weight loss of $14.8 \%$ at the end of the programme was associated with a $49 \%$ reduction in prescription costs at 1 year. Data from a modelling study in the general population also suggest that a weight loss of $10 \%$ may yield substantial long-term economic benefits, mostly owing to reductions in the costs of type 2 diabetes, coronary heart disease and hypertension. ${ }^{[37]}$ Lifetime economic costs were reduced by up to \$US5300 (year 1996 values) with the greatest benefits in patients at the highest initial BMI levels. Results obtained from a recent study that analysed the clinical and economic benefits of bariatric surgery in obese (BMI $\geq 35 \mathrm{~kg} / \mathrm{m}^{2}$ ) diabetic patients support the conclusion made in this study. ${ }^{[21]}$

The present study has certain limitations. First, the economic benefit associated with weight loss was measured over a short-term period of 12 months. Further data are required on the effect of weight and/or BMI change on long-term direct costs in patients with type 2 diabetes, together with the factors that underlie variations in weight. Second, the measurement of BMI change in parallel with 1-year direct costs may confound the interpretation of the relationship between these variables because events such as hospitalization and emergency room visits could contribute to a change in BMI or weight, as well as to the related medical cost. Third, because of bureaucratic difficulties, centres across all Spanish regions but two (País Vasco and Navarra) participated in the study; these two regions represent around $6.1 \%^{[38]}$ of the national population. 


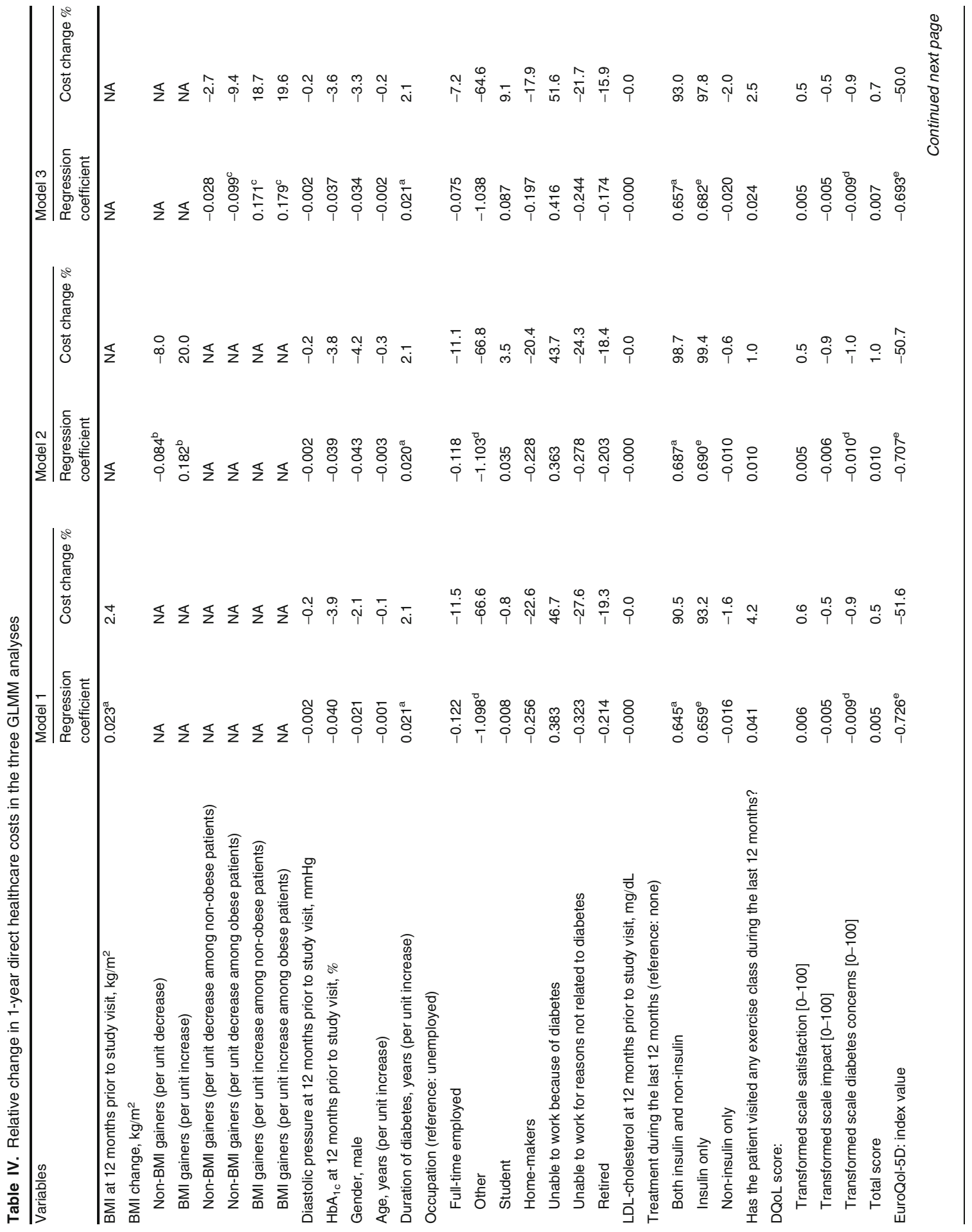




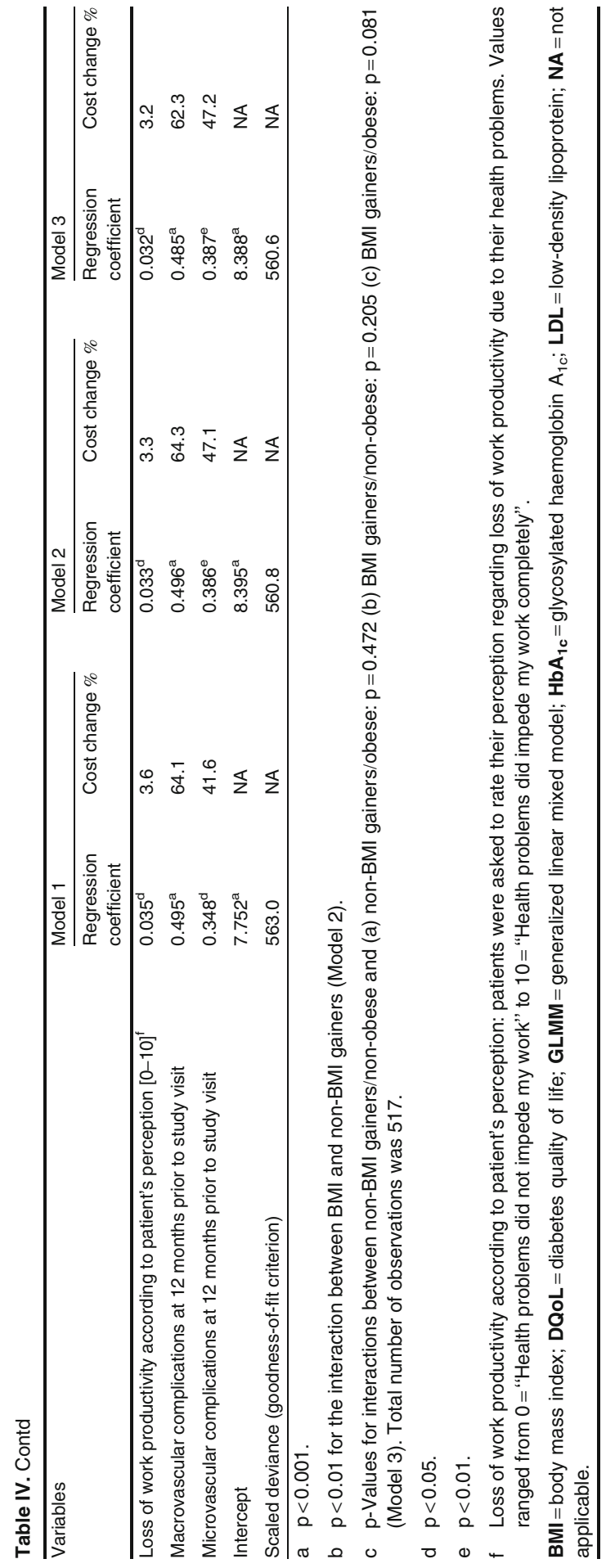

Fourth, due to the observational nature of the study, the data registry started after patients had signed the informed consent, therefore patient response rate has not been collected. Fifth, because of the way data have been collected, it was not possible to separate cost into that attributable to diabetes, diabetic complications and comorbidities. Sixth, due to missing values, only data of 517 patients could be used; despite the fact that no obvious differences were observed between these 517 patients and the overall 738, this could nevertheless have weakened the generalization of the findings. Seventh, the study cannot explain the possible reasons for BMI or weight change during the reference period. Many factors could have contributed to the observed changes, including diabetes- and non-diabetesrelated medications, diet, physical exercise, disease severity, and other related co-morbidities. In the future, the economic consequences of BMI or weight change should ideally be studied in various subgroups categorized by gender, age, duration of diabetes, diabetes-related complications, diabetes treatment and selected co-morbidities. Lastly, data on healthcare resource utilization were collected retrospectively and therefore may not be complete. An attempt was made to overcome this problem by asking patients to complete this information, where necessary, at the study visit.

\section{Conclusions}

An increase in BMI among patients with type 2 diabetes in Spain was associated with increased 1-year direct healthcare costs. A reduction in BMI was associated with appreciable short-term economic benefits, especially in obese patients.

\section{Acknowledgements}

This study was supported by Lilly, Spain. The authors acknowledge editorial and project management assistance provided by Rx Communications Ltd, Mold, UK (funded by Lilly, Spain).

T. Dilla, C. Nicolay and J. Reviriego are employees of Lilly. A. Valladares and M. Costi were employees of Lilly at the time that the work for this manuscript was planned and performed. J. Salvador has participated in consultant activities for Lilly, Novartis and Boehringer Ingelheim. 


\section{References}

1. European Region and Federation of European Nurses in Diabetes. Diabetes - the policy puzzle: is Europe making progress? (2nd ed). International Diabetes Federation, 2010. Available from URL: http://ec.europa.eu/health/ major_chronic_diseases/docs/policy_puzzle_2008.pdf [Accessed 2012 Aug 30]

2. Shaw JE, Sicree RA, Zimmet PZ. Global estimates of the prevalence of diabetes for 2010 and 2030. Diabetes Res Clin Pract 2010 Jan; 87 (1): 4-14

3. International Diabetes Federation. Prevalence estimates of diabetes mellitus (DM), 2010. International Diabetes Federation, Brussels 2010. Available from URL: http://www. diabetesatlas.org/content/prevalence-estimates-diabetes-mel litus-dm-2010] [Accessed 2010 May 24]

4. American Diabetes Association. Diagnosis and classification of diabetes mellitus. Diabetes Care 2005 Jan; 28 Suppl. 1: S37-42

5. Fu AZ, Qiu Y, Radican L, et al. Health care and productivity costs associated with diabetic patients with macrovascular comorbid conditions. Diabetes Care 2009 Dec; 32 (12): 2187-92

6. Jendle JH. Resource utilisation and costs for the treatment of diabetes in the developed world: an economical burden that needs to be solved. Int J Clin Pract 2009 Jul; 63 (7): 980-2

7. Oliva J, Lobo F, Molina B, et al. Direct health care costs of diabetic patients in Spain. Diabetes Care 2004 Nov; 27 (11): 2616-21

8. Mata $\mathrm{M}$, Antoñanzas $\mathrm{F}$, Tafalla $\mathrm{M}$, et al. The cost of type 2 diabetes in Spain: the CODE-2 study [in Spanish]. Gac Sanit 2002 Nov-Dec; 16 (6): 511-20

9. Ballesta M, Carral F, Olveira G, et al. Economic cost associated with type II diabetes in Spanish patients. Eur J Health Econ 2006 Dec; 7 (4): 270-5

10. González P, Faure E, Del Castillo A, et al. Cost of diabetes mellitus in Spain [in Spanish]. Med Clin (Barc) 2006 Nov; 127 (20): 776-84

11. Jurado J, Ybarra J, Solanas P, et al. Prevalence of cardiovascular disease and risk factors in a type 2 diabetic population of the North Catalonia diabetes study. J Am Acad Nurse Pract 2009 Mar; 21 (3): 140-8

12. Serrano Rios M. Relationship between obesity and the increased risk of major complications in non-insulin-dependent diabetes mellitus. Eur J Clin Invest 1998 Sep; 28 Suppl. 2: 14-7, discussion 17-8

13. World Health Organization. Obesity: Preventing and managing the global epidemic. Report of a WHO Consultation [WHO Technical Report Series 894]. Geneva: WHO, 2000

14. Dilla T, Costi M, Boye KS, et al. The impact of obesity in the management and evolution of diabetes mellitus [in Spanish]. Rev Clin Esp 2008 Oct; 208 (9): 437-43

15. Laguna S, Príncipe RM, Botella S, et al. El índice de masa corporal y la circunferencia abdominal infraestiman el diagnóstico de obesidad en pacientes con diabetes mellitus tipo 2. Av. Diabetol 2010; 26: 173-7

16. Must A, Spadano J, Coakley EH, et al. The disease burden associated with overweight and obesity. JAMA 1999 Oct; 282 (16): $1523-9$
17. Hernández-Mijares A, Solá-Izquierdo E, Ballester-Mechó $\mathrm{F}$, et al. Obesity and overweight prevalences in rural and urban populations in East Spain and its association with undiagnosed hypertension and Diabetes Mellitus: a crosssectional population-based survey. BMC Res Notes 2009 Jul; 2: 151

18. Rana JS, Nieuwdorp M, Jukema JW, et al. Cardiovascular metabolic syndrome: an interplay of, obesity, inflammation, diabetes and coronary heart disease. Diabetes Obes Metab 2007 May; 9 (3): 218-32

19. Alegría Ezquerra E, Castellano Vázquez JM, Alegría Barrero A. Obesity, metabolic syndrome and diabetes: cardiovascular implications and therapy [in Spanish]. Rev Esp Cardiol 2008 Jul; 61 (7): 752-64

20. Klein S, Ghosh A, Cremieux PY, et al. Economic impact of the clinical benefits of bariatric surgery in diabetes patients with BMI $\geq 35 \mathrm{~kg} / \mathrm{m}^{2}$. Obesity (Silver Spring) 2011 Mar; 19 (3): 581-7

21. Lloyd A, Sawyer W, Hopkinson P. Impact of long-term complications on quality of life in patients with type 2 diabetes not using insulin. Value Health 2001 Sep-Oct; 4 (5): 392-400

22. Koopmanschap M, CODE-2 Advisory Board. Coping with type II diabetes: the patient's perspective. Diabetologia 2002 Jul; 45 (7): S18-22

23. Sach TH, Barton GR, Doherty M, et al. The relationship between body mass index and health-related quality of life: comparing the EQ-5D, EuroQol VAS and SF-6D. Int J Obes (Lond) 2007 Jan; 31 (1): 189-96

24. Banegas JR, López-García E, Graciani A, et al. Relationship between obesity, hypertension and diabetes, and health-related quality of life among the elderly. Eur J Cardiovasc Prev Rehabil 2007 Jun; 14 (3): 456-62

25. de Leiva A. What are the benefits of moderate weight loss? Exp Clin Endocrinol Diabetes 1998; 106 Suppl. 2: 10-3

26. Williams KV, Kelley DE. Metabolic consequences of weight loss on glucose metabolism and insulin action in type 2 diabetes. Diabetes Obes Metab 2000 Jun; 2 (3): 121-9

27. Vidal J. Updated review on the benefits of weight loss. Int J Obes Relat Metab Disord 2002 Dec; 26 Suppl. 4: S25-8

28. Oblikue Consulting Health. Base de Datos de Costes Sanitarios eSALUD. Barcelona, 2008. Available from URL: http://www.oblikue.com/bddcostes/ [Accessed 2009 Feb 18]

29. General Spanish Council of Pharmacists. BOT database of pharmaceutical prices, 2008 [online]. Available from URL: https://botplusweb.portalfarma.com/ [Accessed 2012 Aug 30]

30. The EuroQol Group. EuroQol - a new facility for the measurement of health-related quality of life. Health Policy 1990 Dec; 16 (3): 199-208

31. Reviriego J, Millan MD, Millan M. Evaluation of the diabetes quality-of-life questionnaire in a Spanish population: an experience of translation and reliability. Pharmacoeconomics 1996 Dec; 10 (6): 614-22

32. Basu A, Manning WG, Mullahy J. Comparing alternative models: $\log$ vs. Cox proportional hazard? Health Econ 2004 Aug; 13 (8): 749-65

33. Yu AP, Wu EQ, Birnbaum HG, et al. Short-term economic impact of body weight change among patients with type 2 diabetes treated with antidiabetic agents: analysis using claims, laboratory, and medical record data. Curr Med Res Opin 2007 Sep; 23 (9): 2157-69 
34. Heithoff KA, Cuffel BJ, Kennedy S, et al. The association between body mass and health care expenditures. Clin Ther 1997 Jul-Aug; 19 (4): 811-20

35. Brandle M, Zhou H, Smith BR, et al. The direct medical cost of type 2 diabetes. Diabetes Care 2003 Aug; 26 (8): 2300-4

36. Collins RW, Anderson JW. Medication cost savings associated with weight loss for obese non-insulin-dependent diabetic men and women. Prev Med 1995 Jul; 24 (4): 369-74

37. Oster G, Thompson D, Edelsberg J, et al. Lifetime health and economic benefits of weight loss among obese persons. Am J Public Health 1999 Oct; 89 (10): 1536-42
38. National Institute of Statistics. Census 2001 population figures by autonomous community and sex: data from year 2007[online]. Available from URL: http://www.ine.es/en/ welcome_en.htm [Accessed 2012 Mar 23]

Correspondence: Dr T. Dilla, PharmD, Health Outcomes Research Unit, Medical Department, Lilly S.A., Avenida de la Industria, 30, 28108, Alcobendas, Madrid, Spain E-mail: dilla_tatiana@lilly.com 